\title{
Does food insufficiency in childhood contribute to dementia in later life?
}

\author{
This article was published in the following Dove Press journal: \\ Clinical Interventions in Aging \\ 17 December 2014 \\ Number of times this article has been viewed
}

\author{
Yadollah Abolfathi \\ Momtaz ${ }^{1,4}$ \\ Sharifah Azizah Haron ${ }^{1,3}$ \\ Tengku Aizan Hamid ${ }^{1,2}$ \\ Rahimah Ibrahim ${ }^{1,2}$ \\ Jariah Masud' \\ 'Institute of Gerontology, Universiti \\ Putra Malaysia, Serdang, Selangor, \\ Malaysia; ${ }^{2}$ Department of Human \\ Development and Family Studies, \\ Faculty of Human Ecology, Universiti \\ Putra Malaysia, Serdang, Selangor, \\ Malaysia; ${ }^{3}$ Department of Resource \\ Management and Consumer Studies, \\ Faculty of Human Ecology, Universiti \\ Putra Malaysia, Serdang, Selangor, \\ Malaysia; ${ }^{4}$ Iranian Research Center on \\ Aging, University of Social Welfare and \\ Rehabilitation Sciences, Tehran, Iran
}

Correspondence: Tengku Aizan Hamid Institute of Gerontology, Universiti Putra Malaysia, 43400 UPM, Serdang, Selangor, Malaysia

Tel +60389472750

Fax +60 389472738 ,

Email aizan@upm.edu.my

\begin{abstract}
Background: Despite several studies attempting to identify the risk factors for dementia, little is known about the impact of childhood living conditions on cognitive function in later life. The present study aims to examine the unique contribution of food insufficiency in childhood to dementia in old age.

Methods: Data for this study of 2,745 older Malaysians aged 60 years and older was obtained from a national survey entitled "Mental Health and Quality of Life of Older Malaysians" conducted from 2003 through 2005 using a cross-sectional design. The Geriatric Mental StateAutomated Geriatric Examination for Computer Assisted Taxonomy was used to measure dementia. A multiple binary logistic regression using Statistical Package for Social Sciences version 21 was conducted to assess the unique effect of food insufficiency in childhood on developing dementia in old age.

Results: A notably higher prevalence of dementia was found in respondents who indicated they had experienced food insufficiency in childhood than in their food-sufficient counterparts ( $23.5 \%$ versus $14.3 \%$ ). The findings from multiple logistic regression analysis revealed that food insufficiency in childhood would independently increase the risk of developing dementia in old age by $81 \%$, after adjusting for sociodemographic factors (odds ratio $=1.81,95 \%$ confidence interval 1.13-2.92, $P<0.01$ ).

Conclusion: Findings from the present study showing that food insufficiency in early life significantly contributes to dementia in later life highlight the importance of childhood living conditions in maintaining cognitive function in old age. It is, therefore, suggested that older adults with childhood food insufficiency might be targeted for programs designed to prevent dementia.
\end{abstract}

Keywords: aged, dementia, food insufficiency, Malaysia

\section{Introduction}

It has been projected that there will be 29 million people living with dementia worldwide by 2020 , with one new case every 7 seconds. ${ }^{1}$ With regard to the profound effect of dementia on lives of elderly persons and public health costs, in recent years, a growing interest has been raised to identify risk factors for cognitive impairment in old age. $^{2}$ In light of this consideration, several studies have attempted to find factors that may be associated with dementia and have determined that age, sex, ethnicity, genetic factors, socioeconomic status, life style, hypertension, cardiovascular diseases, stroke, diabetes, and depression may be involved. ${ }^{3-5}$ However, most of these studies have focused on risk factors in adulthood rather than in early life, when susceptibility may be high. Hence, less is known about the impact of childhood living conditions on cognitive impairment in late life. Yet, only recently, research has begun to identify the cause of dementia from earlier life and found that higher childhood socioeconomic status is associated with better cognitive functioning in old age. ${ }^{6-8}$ In contrast, poor 
childhood living conditions may put people at higher risk for dementia. ${ }^{9}$ Most existing research has been conducted in developed countries, with little attention to the childhood living conditions of older adults from developing countries, such as Malaysia, where early life conditions were much worse than those living in developed countries. In Malaysia, older adults who were born before independence in 1957 have experienced hard living conditions due to World War II, when Malaya was under Japanese occupation between 1941 and 1945. It was reported that as the war progressed, all three major ethnic communities began to suffer deprivation from increasingly severe rationing, hyperinflation, and a lack of resources. Consequently, they suffered from hunger and malnutrition as a result of food insufficiency. ${ }^{10,11}$

In addition, since previous studies have found that food insufficiency in childhood contributes to some medical conditions that may raise the risk for dementia in old age, such as hypertension, diabetes mellitus, depression, ${ }^{12-14}$ it is therefore imperative to assess whether food insufficiency in childhood may contribute to dementia in old age.

\section{Methods}

Data for this study involving 2,745 older Malaysians aged 60 years and older were obtained from the Mental Health and Quality of Life of Older Malaysians (MHQoLOM). Detailed description of the method has previously been published elsewhere. ${ }^{15}$ Briefly, the MHQoLOM is a community based, cross-sectional survey, which was conducted throughout Malaysia from 2003 to 2005. The survey employed a multistage, random sampling technique to select the sample. Data collection was conducted through face-toface interviews by trained interviewers. Eligible criteria for respondent selection were 1) older Malaysian aged 60 years and older, 2) capable of orally completing the questionnaire, 3) living in the community, and 4) capable of written informed consent. Exclusion criteria for this survey were those who were bedridden and living in institutions.

\section{Measures}

\section{Food insufficiency}

Food insufficiency, which refers to an inadequate amount of food intake because of financial resources, ${ }^{16}$ was assessed using a single item. Respondents were asked to describe the food eaten in their childhood as "enough food to eat," "sometimes not enough food to eat," or "often not enough food to eat." The indicator has been used to measure food deprivation by the US Department of Agriculture since the mid-1970s. This single item has demonstrated good face validity. ${ }^{17}$ In the present study, those who reported not having enough food to eat in their childhood were considered food insufficient.

\section{Dementia}

The dependent variable of interest for this study is dementia, which was determined by the Malaysian-adapted and validated version of Geriatric Mental State-Automated Geriatric Examination for Computer Assisted Taxonomy (GMSAGECAT). Validation of the Malaysian version of GMSAGECAT against clinical assessment of dementia revealed an overall agreement of $76.2 \%(n=105)$ with a moderate kappa value of $0.502 .^{4}$ The GMS-AGECAT has been widely used and applied with good levels of agreement in a variety of settings. The scores of 3 or higher on the GMS-AGECAT were considered as dementia. ${ }^{18,19}$ In the current study, the GMS-AGECAT was administered by trained enumerators.

\section{Control variables}

To assess the unique effect of food insufficiency on dementia, several sociodemographic variables previously shown to influence dementia were chosen. These potential sociodemographic factors included age, sex, marital status, educational attainment, ethnicity, and stratum (place of residence). ${ }^{15,20}$

\section{Statistical analysis}

The Statistical Package for Social Sciences version 21 for Windows (IBM Corporation, Armonk, NY, USA) was used to analyze the data. A multiple binary logistic regression was conducted to determine the unique impact of food insufficiency on dementia, while adjusting for previously identified sociodemographic factors.

\section{Ethical considerations}

The study was conducted in accordance with the World Medical Association Helsinki Declaration and approved by the Ministry of Health, Malaysia. Oral informed consent was obtained from all respondents after having the objectives of the study explained by a trained interviewer.

\section{Results}

Table 1 presents background characteristics for the sample used in this analysis by dementia status. Among 2,745 respondents interviewed in the survey, $1,381(50.3 \%)$ were male and 1,364 (49.7\%) were female. The mean age of the respondents at the time of the interview was 70.46 years (standard deviation $=7.22$, range 60-104 years). The majority of respondents (72.5\%) were aged 60-74 years (young-old) and $4.7 \%$ were aged 85 years and older (oldest-old age 
Table I Background characteristics of the sample by dementia status

\begin{tabular}{|c|c|c|c|c|c|c|c|}
\hline & \multicolumn{2}{|l|}{ Total } & \multicolumn{2}{|c|}{ No dementia } & \multicolumn{2}{|c|}{ Dementia } & \multirow[t]{2}{*}{$\chi^{2}$} \\
\hline & $\mathbf{n}$ & $\%$ & $\mathbf{n}$ & $\%$ & $\mathbf{n}$ & $\%$ & \\
\hline \multicolumn{8}{|l|}{ Age } \\
\hline Young-old (60-74 years) & 1,985 & 72.5 & $|, 76|$ & 88.7 & 224 & 11.3 & $78.19 * * *$ \\
\hline Old-old (75-84 years) & 624 & 22.8 & 489 & 78.4 & 135 & 21.6 & \\
\hline Oldest-old (85 plus years) & 129 & 4.7 & 86 & 66.7 & 43 & 33.3 & \\
\hline \multicolumn{8}{|l|}{ Sex } \\
\hline Female & 1,364 & 49.7 & 1,080 & 79.2 & 284 & 20.8 & $80.47 * * *$ \\
\hline Male & $\mathrm{I}, 38 \mathrm{I}$ & 50.3 & 1,261 & 91.3 & 120 & 8.7 & \\
\hline \multicolumn{8}{|l|}{ Marital status } \\
\hline Not married & 1,217 & 44.4 & 974 & 80.0 & 243 & 20.0 & $48.37 * * *$ \\
\hline Now married & I,524 & 55.6 & 1,364 & 89.5 & 160 & 10.5 & \\
\hline \multicolumn{8}{|l|}{ Ethnicity } \\
\hline Non-Bumiputera & 839 & 30.6 & 781 & 93.1 & 58 & 6.9 & $58.64 * * *$ \\
\hline Malay and Bumiputera & 1,906 & 69.4 & 1,560 & 81.8 & 346 & 18.2 & \\
\hline \multicolumn{8}{|l|}{ Education } \\
\hline No formal & 1,219 & 45.1 & 909 & 74.6 & 310 & 25.4 & $206.96 * 1 *$ \\
\hline Primary & $\mathrm{I}, 208$ & 44.7 & 1,126 & 93.2 & 82 & 6.8 & \\
\hline Secondary and tertiary & 278 & 10.3 & 272 & 97.8 & 6 & 2.2 & \\
\hline \multicolumn{8}{|l|}{ Stratum } \\
\hline Rural & 1,183 & 43.1 & 951 & 80.4 & 232 & 19.6 & $39.66 * * *$ \\
\hline Urban & I,562 & 56.9 & 1,390 & 89.0 & 172 & 11.0 & \\
\hline \multicolumn{8}{|l|}{ Food insufficiency } \\
\hline No & 2,626 & 95.7 & 2,250 & 85.7 & 376 & 14.3 & $7.70 * *$ \\
\hline Yes & 119 & 4.3 & 91 & 76.5 & 28 & 23.5 & \\
\hline
\end{tabular}

Notes: $* * P<0.01, * * * P<0.001$.

group). As can be seen in Table 1, a significant proportion of the respondents ( $44 \%$ ) had no formal education, followed by primary education (44.5\%) and secondary and tertiary education $(10.3 \%)$. In terms of marital status, $55.6 \%$ were married, $41.5 \%$ widowed, and the rest $(2.9 \%)$ were never married or divorced. Of the respondents, $4.3 \%$ reported they had experienced not having enough to eat in childhood. The prevalence of dementia in older adults with food insufficiency in childhood was considerably higher compared to their food-sufficient counterparts (23.5\% versus $14.3 \%)$. The results of chi-square analyses, which are shown in Table 1 , show significant association between dementia with age $\left(\chi^{2}=78.19, P<0.001\right), \operatorname{sex}\left(\chi^{2}=80.47, P<0.01\right)$, marital status $\left(\chi^{2}=48.37, P<0.001\right)$, ethnicity $\left(\chi^{2}=58.64, P<0.001\right)$, education $\left(\chi^{2}=206.96, P<0.001\right)$, stratum $\left(\chi^{2}=39.66, P<0.001\right)$, and starvation $\left(\chi^{2}=7.70, P<0.01\right)$.

\section{Multiple binary logistic regression}

Does food insufficiency in early life increase the risk of dementia in later life? To answer this question, a multiple binary logistic regression analysis was conducted to assess the unique effect of food insufficiency in childhood on developing dementia in old age after controlling for previously identified sociodemographic factors. Table 2 displays results of multiple binary logistic regression analysis. The Hosmer-Lemeshow test showed that the model fits the data well $\left(\chi^{2}[8]=10.10, P=0.258\right)$. After adjusting for the effects of the covariates including age, sex, marital status, ethnicity, stratum, and education, food insufficiency in childhood significantly contributed to dementia in old age (odds ratio $=1.81,95 \%$ confidence interval 1.13-2.92, $P<0.01)$.

Table 2 Results of multiple logistic regression

\begin{tabular}{lllllll}
\hline Variable & B & SE & OR & \multicolumn{2}{c}{$\mathbf{9 5 \% ~ C l ~ f o r ~ O R ~}$} \\
\cline { 5 - 7 } & & & & Lower & Upper \\
\hline Age & & & & & \\
$\quad$ Young-old (60-74 years) & & & & & \\
$\quad$ Old-old (75-84 years) & 0.63 & 0.13 & $1.89^{* * *}$ & 1.46 & 2.44 \\
$\quad$ Oldest-old (85 plus years) & 1.2 & 0.22 & $3.31^{* * *}$ & 2.15 & 5.1 \\
Sex (male) & -0.47 & 0.14 & $0.62^{* * *}$ & 0.47 & 0.82 \\
Marital status (married) & -0.12 & 0.13 & 0.89 & 0.68 & 1.15 \\
Ethnicity (Malay) & 0.88 & 0.16 & $2.42^{* * *}$ & 1.76 & 3.33 \\
Stratum (rural) & 0.28 & 0.12 & $1.32^{*}$ & 1.04 & 1.68 \\
Education (no formal) & & & & & \\
$\quad$ Primary & -1.25 & 0.14 & $0.29 * * *$ & 0.22 & 0.38 \\
$\quad$ Secondary and tertiary & -1.89 & 0.43 & $0.15^{* * *}$ & 0.07 & 0.35 \\
Food insufficiency & 0.6 & 0.24 & $1.81^{* *}$ & 1.13 & 2.92 \\
\hline
\end{tabular}

Notes: $* P<0.05, * * P<0.01, * * * P<0.001$; Hosmer-Lemeshow Test: $\chi^{2}(8)=10.10, P=0.258$. Abbreviations: $\mathrm{Cl}$, confidence interval; $\mathrm{OR}$, odds ratio; $\mathrm{SE}$, standard error; $\mathrm{B}$, logistic regression coefficient. 


\section{Discussion}

As expected, in concordance with previous studies, the findings from this study showed statistically significant association between dementia and age,${ }^{3}$ sex, ${ }^{21}$ marital status, ${ }^{22}$ educational attainment, ${ }^{15}$ ethnicity, ${ }^{4}$ and stratum. ${ }^{23}$

In line with the main purpose of the study, the findings showed that food insufficiency in early life independently increases the risk of developing dementia in old age by $81 \%$. This result is consistent with the findings from previous studies, which have demonstrated that socioeconomic status in childhood influences cognitive function in later life. ${ }^{2,6,9,24}$ To our knowledge, however, few scientific investigations have examined whether food insufficiency in childhood influences dementia in old age. For example, Zhang et $\mathrm{al}^{8}$ found that frequent hunger was associated with higher risk of cognitive impairment among a sample of the oldest old Chinese.

According to the literature, food insufficiency may contribute to dementia through two potential models, namely the latency and pathway models. The latency model suggests that childhood living conditions directly affect late-life health outcomes. The brain grows most during the prenatal period and in childhood and continues to complete its maturation during adolescence. It was found that the areas of the brain that take longest to mature during childhood and adolescence are the same areas of the brain that show the earliest signs of dementia. ${ }^{9,25}$ Impaired development of the brain due to early life malnutrition can cause less efficient brain function. The negative effects of impaired brain development may remain small until aggravated by the aging process. ${ }^{9}$ However, the pathway model suggests that childhood living conditions may indirectly influence cognitive impairment. ${ }^{8}$ For example, poor early life conditions can increase the risk for several chronic conditions such as depression, ${ }^{26}$ hypertension, ${ }^{27}$ diabetes mellitus, ${ }^{12}$ and obesity, ${ }^{28}$ which in turn affect latelife cognitive functioning.

\section{Limitations of the study}

The first limitation of the current study that should be addressed is the retrospective nature of data collection for food insufficiency in childhood, which may raise concern of recall bias. However, a recent study found that respondents well remember their living conditions in early life. ${ }^{29}$ Second, the single-item measurement of food insufficiency may provide a less comprehensive picture of food status than the multi-item, which would give respondents more opportunity to identify this experience. Despite this limitation of the single-item measure, several studies have shown that single-item measures of food insufficiency have high face-validity and high correlation between single-item measures of food insufficiency and scaled measures. ${ }^{30-33}$ Third, although the present study benefits from the inclusion of a large representative sample of older Malaysians 60 years and older, its cross-sectional design prohibits conclusions about causality.

\section{Conclusion}

The findings from the present study show that food insufficiency in early life significantly increases the risk of dementia in later life after controlling for various adulthood sociodemographic factors. These findings imply that health and social care professionals should be mindful of the increased risk of dementia in persons who have experienced food insufficiency in childhood. It is, therefore, suggested that older adults with childhood food insufficiency might be targeted for programs designed to prevent dementia. Future research should explore the potential moderating factors that may reduce negative effects of poor childhood living conditions on the cognitive function of older adults.

\section{Acknowledgments}

This study was financially supported by the Ministry of Science, Technology and the Environment (Grant number: IRPA 06-02-04-0461PR0031).

\section{Disclosure}

The authors report no conflicts of interest in this work.

\section{References}

1. Haan MN, Wallace R. Can dementia be prevented? Brain aging in a population-based context. Annu Rev Public Health. 2004;25:1-24.

2. Fors S, Lennartsson C, Lundberg O. Childhood living conditions, socioeconomic position in adulthood, and cognition in later life: exploring the associations. J Gerontol B Psychol Sci Soc Sci. 2009;64(6):750-757.

3. Chen JH, Lin KP, Chen YC. Risk factors for dementia. J Formos Med Assoc. 2009;108(10):754-764.

4. Momtaz YA, Hamid TA, Yusoff S, Ibrahim R. Do depression and educational attainment mediate the association between ethnicity and dementia? Gerontology. 2013;59(3):206-212.

5. Launer LJ, Andersen K, Dewey ME, et al. Rates and risk factors for dementia and Alzheimer's disease: results from EURODEM pooled analyses. EURODEM Incidence Research Group and Work Groups. European Studies of Dementia. Neurology. 1999;52(1):78-84.

6. Kaplan GA, Turrell G, Lynch JW, Everson SA, Helkala EL, Salonen JT. Childhood socioeconomic position and cognitive function in adulthood. Int J Epidemiol. 2001;30(2):256-263.

7. Luo Y, Waite LJ. The impact of childhood and adult SES on physical, mental, and cognitive well-being in later life. J Gerontol B Psychol Sci Soc Sci. 2005;60(2):S93-S101.

8. Zhang Z, Gu D, Hayward MD. Early life influences on cognitive impairment among oldest old Chinese. J Gerontol B Psychol Sci Soc Sci. 2008;63(1):S25-S33.

9. Moceri VM, Kukull WA, Emanuel I, van Belle G, Larson EB. Early-life risk factors and the development of Alzheimer's disease. Neurology. 2000;54(2):415-420. 
10. Kratoska PH. The Japanese Occupation of Malaya: A Social and Economic History. Honolulu: University of Hawaii Press; 1997.

11. Champion M, Moreira J. History of Malaya and Southeast Asia. Singapore: EPB Publishers Pte Ltd; 1995.

12. Khoroshinina LP, Zhavoronkova NV. [Starving in childhood and diabetes mellitus in elderly age]. Adv Gerontol. 2008;21(4):684-687. Russian.

13. Kuh D, Ben-Shlomo Y, Lynch J, Hallqvist J, Power C. Life course epidemiology. J Epidemiol Community Health. 2003;57(10):778-783.

14. Murray ET, Hardy R, Strand BH, Cooper R, Guralnik JM, Kuh D. Gender and life course occupational social class differences in trajectories of functional limitations in midlife: findings from the 1946 British birth cohort. J Gerontol A Biol Sci Med Sci. 2011;66(12):1350-1359.

15. Hamid TA, Krishnaswamy S, Abdullah SS, Momtaz YA. Sociodemographic risk factors and correlates of dementia in older Malaysians. Dement Geriatr Cogn Disord. 2010;30(6):533-539.

16. Nelson K, Cunningham W, Andersen R, Harrison G, Gelberg L. Is food insufficiency associated with health status and health care utilization among adults with diabetes? J Gen Intern Med. 2001;16(6):404-411.

17. Vozoris NT, Tarasuk VS. Household food insufficiency is associated with poorer health. $J$ Nutr. 2003;133(1):120-126.

18. Momtaz YA, Hamid TA, Ibrahim R. Gastritis may boost odds of dementia. Am J Alzheimers Dis Other Demen. 2014;29(5):452-456.

19. Holwerda TJ, Deeg DJ, Beekman AT, et al. Feelings of loneliness, but not social isolation, predict dementia onset: results from the Amsterdam Study of the Elderly (AMSTEL). J Neurol Neurosurg Psychiatry. 2014; 85(2):135-142.

20. Momtaz YA, Hamid TA, Ibrahim R. The impact of mild cognitive impairment on sexual activity. Am J Alzheimers Dis Other Demen. 2013; 28(8):759-762.

21. Li G, Shen YC, Chen CH, Zhao YW, Li SR, Lu M. An epidemiological survey of age-related dementia in an urban area of Beijing. Acta Psychiatr Scand. 1989;79(6):557-563.

22. Helmer C. Dementia and marital status at midlife and late life. BMJ. 2009;339:b1690.
23. Jia J, Wang F, Wei C, et al. The prevalence of dementia in urban and rural areas of China. Alzheimers Dement. 2014;10(1):1-9.

24. Everson-Rose SA, Mendes de Leon CF, Bienias JL, Wilson RS, Evans DA. Early life conditions and cognitive functioning in later life. Am J Epidemiol. 2003;158(11):1083-1089.

25. Kim JM, Stewart R, Shin IS, Yoon JS. Limb length and dementia in an older Korean population. J Neurol Neurosurg Psychiatry. 2003;74(4): $427-432$.

26. Zheng W, Schimmele CM. Food insufficiency and depression. Sociol Perspect. 2005;48(4):481-504.

27. Tennant IA, Barnett AT, Thompson DS, et al. Impaired cardiovascular structure and function in adult survivors of severe acute malnutrition. Hypertension. 2014;64(3):664-671.

28. Adams EJ, Grummer-Strawn L, Chavez G. Food insecurity is associated with increased risk of obesity in California women. J Nutr. 2003;133(4): 1070-1074.

29. Mazzonna F, Havari E. Can we trust older people's statements on their childhood circumstances? Evidence from SHARELIFE. SHARE Wording Paper Series; 2011. Available from: http://ssrn.com/ abstract=2004299. Accessed January 20, 2014.

30. Vogenthaler NS, Hadley C, Lewis SJ, Rodriguez AE, Metsch LR, del Rio C. Food insufficiency among HIV-infected crack-cocaine users in Atlanta and Miami. Public Health Nutr. 2010;13(9):1478-1484.

31. Alaimo K, Briefel RR, Frongillo EA, Olson CM. Food insufficiency exists in the United States: results from the third National Health and Nutrition Examination Survey (NHANES III). Am J Public Health. 1998;88(3):419-426.

32. Siefert K, Heflin CM, Corcoran ME, Williams DR. Food insufficiency and physical and mental health in a longitudinal survey of welfare recipients. J Health Soc Behav. 2004;45(2):171-186.

33. Baggett TP, Singer DE, Rao SR, O'Connell JJ, Bharel M, Rigotti NA. Food insufficiency and health services utilization in a national sample of homeless adults. J Gen Intern Med. 2011;26(6):627-634.
Clinical Interventions in Aging

\section{Publish your work in this journal}

Clinical Interventions in Aging is an international, peer-reviewed journal focusing on evidence-based reports on the value or lack thereof of treatments intended to prevent or delay the onset of maladaptive correlates of aging in human beings. This journal is indexed on PubMed Central, MedLine,

\section{Dovepress}

CAS, Scopus and the Elsevier Bibliographic databases. The manuscript management system is completely online and includes a very quick and fair peer-review system, which is all easy to use. Visit http://www.dovepress. com/testimonials.php to read real quotes from published authors. 